\title{
Model Following Sliding-Mode Control of a Six-Phase Induction Motor Drive
}

\author{
Navid R. Abjadi ${ }^{\dagger}$, Gholamreza Arab Markadeh*, and Jafar Soltani** \\ $\dagger *$ Dept. of Eng., Shahrekord University, Shahrekord, Iran \\ ** Dept. of Electrical and Computer Eng., Isfahan University of Technology, Isfahan, Iran \\ ** Dept. of Eng., Islamic Azad University - Khomeinishahr Branch, Khomeinishahr, Iran
}

\begin{abstract}
In this paper an effective direct torque control (DTC) and stator flux control is developed for a quasi six-phase induction motor (QIM) drive with sinusoidally distributed windings. Combining sliding-mode (SM) control and adaptive input-output feedback linearization, a nonlinear controller is designed in the stationary reference frame, which is capable of tracking control of the stator flux and torque independently. The motor controllers are designed in order to track a desired second order linear reference model in spite of motor resistances mismatching. The effectiveness and capability of the proposed method is shown by practical results obtained for a QIM supplied from a voltage source inverter (VSI).
\end{abstract}

Key Words: Model-following, Multiphase machines, Sliding-mode control

\section{INTRODUCTION}

Recently the use of multiphase machines in various industrial applications especially ones that require more than one electric motor drive such as electric vehicles, textiles, web processing and paper mills has been increasing. The advantages of multiphase machines are their higher torque density, higher efficiency, reduced torque pulsations, greater fault tolerant, improved drive noise characteristic, and a reduction in the required rating per inverter, leg all of which result in simpler and more reliable power conditioning equipment [1]-[7].

Recently, multi-level inverters have been used in many industrial applications [8], [9], in fact multi-phase inverters are the dual of multi-level inverters.

Adjustable speed drives (ASDs) with induction machines (IMs) have been making significant inroads in industry in the last decade. However, they have drawbacks due to their highly coupled nonlinear structure and the errors that occur due to parameter variations, integral drift and noise. In the last two decades some researchers have tried to overcome these problems by applying advance nonlinear control methods to these drives [10]-[12].

Among these methods, the well-known DTC strategy seems to be practically useful for IM drive systems. With the use of DTC, it is possible to obtain good dynamic control of the torque. Classical DTC presents some disadvantages that can

\footnotetext{
Manuscript received Nov. 2, 2009; revised Jun. 25, 2010

$\dagger$ Corresponding Author: navidabjadi@yahoo.com

Tel: +98-9132686959, Fax: +98-381-4424438, Shahrekord Univ.

* Dept. of Eng., Shahrekord University, Iran

** Dept. of Eng., Islamic Azad University - Khomeinishahr Branch, Iran

** Dept. of Electrical and Computer Eng., Isfahan University of Technology, Iran
}

be summarized as: a high current and torque ripple; variable switching frequency behavior; a high noise level at low speeds; and a lack of direct current control [13].

One way to overcome the above drawbacks is with SM control combined with adaptive nonlinear techniques. The SM control objective consists of finding a suitable manifold so that the state trajectories of the plant are restricted to this manifold. Then, determine a switching control law that enforces the state trajectory to this manifold. That is, a control law is determined such that the selected manifold is made attractive and invariant.

In [14] an adaptive SM control is proposed. The controller scheme is implemented in a rotor flux field oriented reference frame. In the adaptive SM control system an adaptive algorithm is utilized to estimate the bound of the uncertainties. The main drawback of this controller is the lack of convergence of the estimated bound to its real value. Even in such adaptive scheme, the estimated bound may become very large and cause chattering. In [15] an adaptive SM control is proposed based on a real-time genetic algorithm which suffers from similar drawbacks. In addition, the controller in [15] needs more calculations. In [16] an adaptive fuzzy SM Control is introduced for IMs. The controller in [16] needs a complicated and time consuming design procedure because of the existence of a fuzzy section. In [17] a fuzzy SM control using an adaptive tuning technique is proposed for an IM. This controller is implemented in a rotor field oriented reference frame which needs a transformation from a stationary reference frame. The sliding surface used in [17] is a proportional-derivative type surface. The derivative amplifies the measurement noise in a closed-loop system.

A nonlinear SM torque control with a third order adaptive 


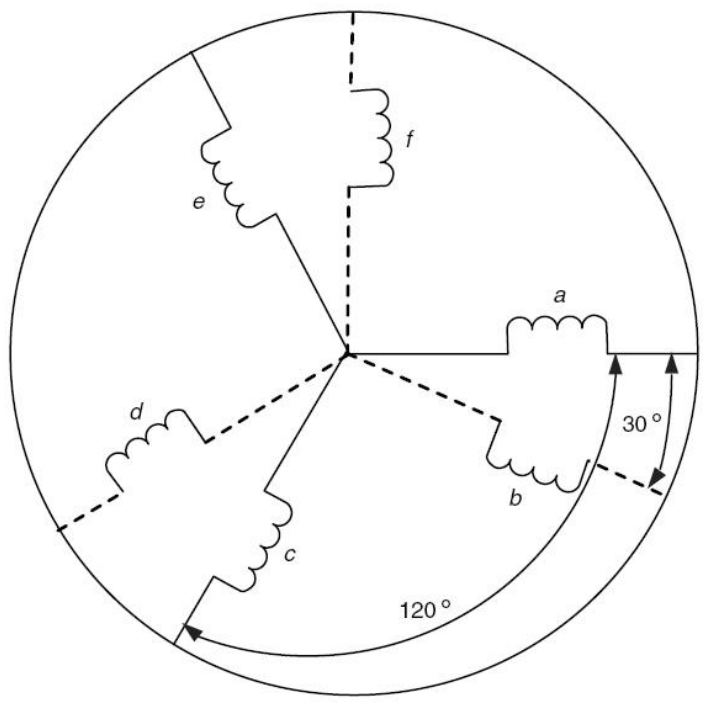

Fig. 1. Representation of a quasi six-phase (split phase, dual three-phase) machine stator winding.

backstepping approach has been presented in [18] for an IM drive system. In [18], the torque and rotor flux are controlled to track a desired linear reference model. Although the composite nonlinear controller of [18] is robust in IM stator and rotor resistance variations and uncertainties, it has some disadvantages in implementation. In fact in designing the third order adaptive backstepping controller, overparameter estimation is mandatory.

In this paper, by combining a nonlinear SM control with an adaptive input-output feedback linearization a robust nonlinear controller is proposed for IMs in general. Since the transient dynamics of the nonlinear system are difficult to evaluate by the linear control theory, like [18] the model-following control technique is utilized for the proposed control to track the designed linear reference model. This controller is utilized on a quasi six-phase IM drive.

The contributions of this paper can be summarized as follows:

A robust nonlinear controller is proposed for IMs in general to achieve: 1) an adaptive SM controller without overparametrization 2) the robustness of nonlinear SM control on a mismatched uncertain system 3) a controller that is implemented in a stationary reference frame and where there is no need for any field oriented reference frame.

The effectiveness and capability of the proposed controller are illustrated by practical results. The proposed controller is used for a quasi six-phase IM drive.

\section{Description AND MOdeling OF THE DRIVE System}

Among the different multiphase drive solutions, one of the most interesting and widely discussed in the literature is the dual three-phase IM having two sets of three-phase windings spatially shifted by 30 electrical degrees (called a quasi-sixphase machine), which is shown in Fig. 1. The neutral points of the two windings should be better isolated for elimination of the zero sequence voltages. Fig. 2 shows such a configuration supplied from a quasi six-phase VSI.
Using the decoupling Clark's transformation, the original phase variables are correlated to new variables as $f_{\alpha \beta x y}=$ $C f_{\text {abcdef }}$, where $\mathrm{C}$ is the power-invariant transformation matrix.

$\begin{array}{cc}\alpha \\ C \\ \beta \\ \frac{2}{\frac{2}{6}} & x \\ y \\ 0+ \\ 0-\end{array}\left[\begin{array}{cccccc}1 & \cos \phi & \cos 4 \phi & \cos 5 \phi & \cos 8 \phi & \cos 9 \phi \\ 0 & \sin \phi & \sin 4 \phi & \sin 5 \phi & \sin 8 \phi & \sin 9 \phi \\ 1 & \cos 5 \phi & \cos 8 \phi & \cos \phi & \cos 4 \phi & \cos 9 \phi \\ 0 & \sin 5 \phi & \sin 8 \phi & \sin \phi & \sin 4 \phi & \sin 9 \phi \\ 1 & 0 & 1 & 0 & 1 & 0 \\ 0 & 1 & 0 & 1 & 0 & 1\end{array}\right]$

where $\phi=\pi / 6$ [19].

Fig. 3 shows the equivalent circuits of a QIM. The stator and rotor voltage equations of the machine are given as [5]:

$$
\begin{gathered}
\left\{\begin{array}{c}
v_{k s}=R_{s} i_{k s}+\frac{d}{d t}\left(L_{s} i_{k s}+L_{m} i_{k r}\right) \quad \text { for } k=\alpha, \beta \\
v_{k s}=R_{s} i_{k s}+\frac{d}{d t}\left(L_{l s} i_{k s}\right) \quad \text { for } k=x, y
\end{array}\right. \\
\left\{\begin{array}{c}
0=R_{r} i_{\alpha r}+\omega_{r}\left(L_{r} i_{\beta r}+L_{m} i_{\beta s}\right)+ \\
\frac{d}{d t}\left(L_{r} i_{\alpha r}+L_{m} i_{\alpha s}\right) \\
0=R_{r} i_{\beta r}-\omega_{r}\left(L_{r} i_{\alpha r}+L_{m} i_{\alpha s}\right)+ \\
\frac{d}{d t}\left(L_{r} i_{\beta r}+L_{m} i_{\beta s}\right)
\end{array}\right.
\end{gathered}
$$

The torque equation of the machine is given by:

$$
T_{e}=P L_{m}\left(i_{\alpha r} i_{\beta s}-i_{\beta r} i_{\alpha s}\right)
$$

where $P$ is the number of pole pairs. It can be seen that the motor $\left(i_{x s}, i_{y s}\right)$ current components do not contribute to torque production. Moreover, it is worthwhile to note that, when the neutral points of the two windings sets of the machine are isolated, the zero sequence components $\left(\boldsymbol{0}^{ \pm}\right)$become zero.

One can see that there is no difference in the $(\alpha, \beta)$ circuit here for a six-phase machine, when compared to the corresponding circuits of a three-phase machine. In principle, any control approach available for a three-phase machine can be used for a multi-phase machine.

\section{INPUT OUTPUT FEEDBACK LINEARIZATION (IOFL) AND SM CONTROLLER}

The state-coordinate transformed model of the machine is expressed by:

$$
\dot{x}=f(x)+g_{1} v_{\alpha s}+g_{2} v_{\beta s}
$$

where $x=\left[\begin{array}{llll}i_{\alpha s} & i_{\beta s} & \lambda_{\alpha s} & \lambda_{\beta s}\end{array}\right]^{T}$ and

$$
f(x)=\left[\begin{array}{c}
-\left(\frac{R_{s}}{\sigma L_{s}}+\frac{R_{r}}{\sigma L_{r}}\right) i_{\alpha s}-\omega_{r} i_{\beta s}+\frac{R_{r}}{L_{S} L_{r}} \lambda_{\alpha s}+\frac{\omega_{r}}{\sigma L_{s}} \lambda_{\beta s} \\
-\left(\frac{R_{s}}{\sigma L_{s}}+\frac{R_{r}}{\sigma L_{r}}\right) i_{\beta s}+\omega_{r} i_{\alpha s}+\frac{R_{r}}{L_{s} L_{r}} \lambda_{\beta s}-\frac{\omega_{r}}{\sigma L_{s}} \lambda_{\alpha s} \\
-R_{s} i_{\alpha s} \\
-R_{s} i_{\beta s}
\end{array}\right]
$$

here $\sigma=1-L_{m}^{2} /\left(L_{r} L_{S}\right)$. 


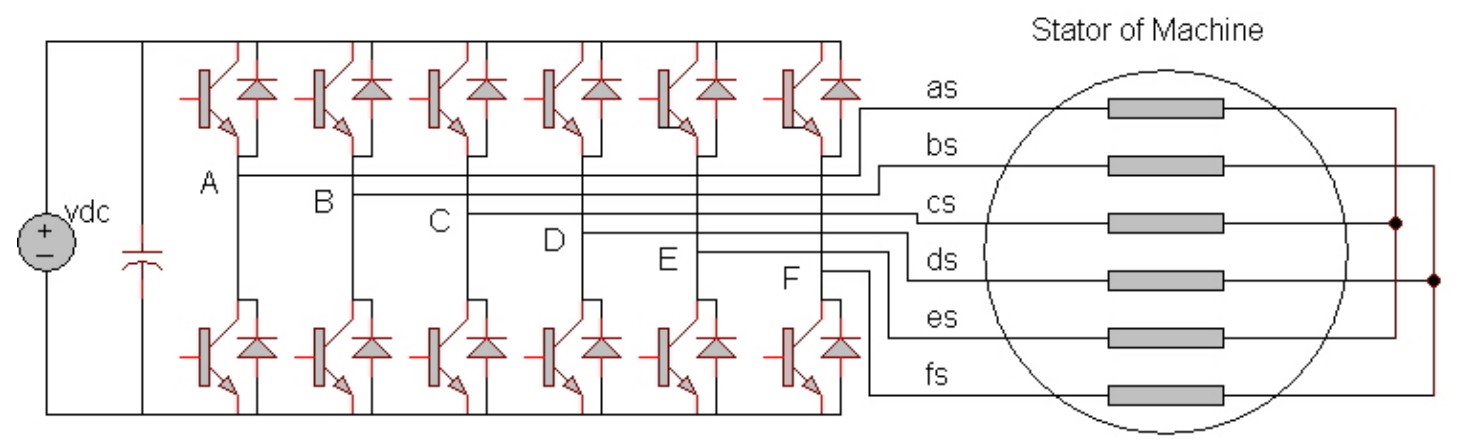

Fig. 2. A six-phase machine drive supplied by a VSI.

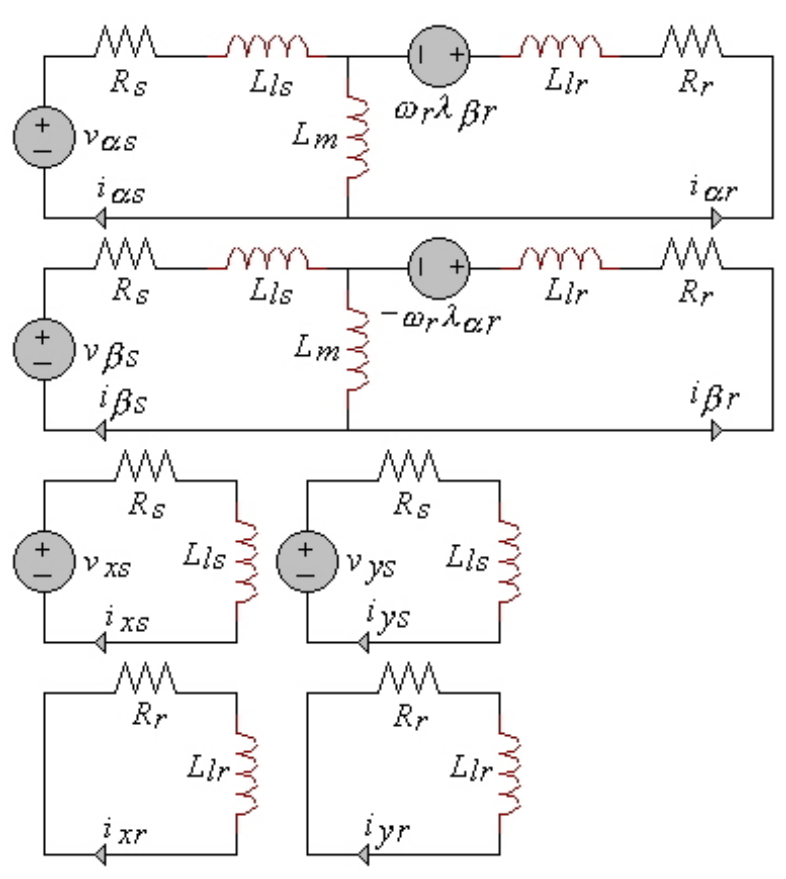

Fig. 3. Equivalent circuits of the QIM.

The generated torque $T_{e}$ and the squared norm of the stator flux linkage $\left(\lambda_{s}^{2}=\lambda_{\alpha s}^{2}+\lambda_{\beta s}^{2}\right)$ are requested to be controlled output. Therefore, let:

$$
\begin{aligned}
& h_{1}(x)=P\left(\lambda_{\alpha s} i_{\beta s}-\lambda_{\beta s} i_{\alpha s}\right) \\
& h_{2}(x)=\lambda_{\alpha s}^{2}+\lambda_{\beta s}^{2} .
\end{aligned}
$$

Define the following change coordinates:

$$
z_{1}=h_{2}(x) \quad z_{2}=h_{1}(x)
$$

The system model shown in (5) is reduced to:

$$
\left[\begin{array}{c}
\dot{z}_{1} \\
\dot{z}_{2}
\end{array}\right]=\left[\begin{array}{c}
L_{f} h_{2} \\
L_{f} h_{1}
\end{array}\right]+\left[\begin{array}{cc}
2 \lambda_{\alpha s} & 2 \lambda_{\beta s} \\
L_{g 1} h_{1} & L_{g 2} h_{1}
\end{array}\right]\left[\begin{array}{c}
v_{\alpha s} \\
v_{\beta s}
\end{array}\right]
$$

here $L_{f}, L_{g 1}$ and $L_{g 2}$ are the Lie derivatives;

$$
\begin{gathered}
L_{f} h_{2}=-2 R_{s}\left(i_{\alpha s} \lambda_{\alpha s}+i_{\beta s} \lambda_{\beta s}\right), \\
L_{g 1} h_{1}=P\left(-\frac{1}{\sigma L_{s}} \lambda_{\beta s}+i_{\beta s}\right),
\end{gathered}
$$

$$
\begin{gathered}
L_{g 2} h_{1}=P\left(\frac{1}{\sigma L_{s}} \lambda_{\alpha s}-i_{\alpha s}\right), \\
L_{f} h_{1}=-P \lambda_{\beta s}\left[-\left(\frac{R_{s}}{\sigma L_{s}}+\frac{R_{r}}{\sigma L_{r}}\right) i_{\alpha s}-\omega_{r} i_{q s}+\frac{\omega_{r}}{\sigma L_{s}} \lambda_{\beta s}\right] \\
+P \lambda_{\alpha s}\left[-\left(\frac{R_{s}}{\sigma L_{s}}+\frac{R_{r}}{\sigma L_{r}}\right) i_{\beta s}+\omega_{r} i_{\alpha s}-\frac{\omega_{r}}{\sigma L_{s}} \lambda_{\alpha s}\right]
\end{gathered}
$$

To achieve decoupling, the following nonlinear state feedback control is employed:

$$
\left[\begin{array}{c}
\hat{v}_{\alpha s} \\
\hat{v_{\beta s}}
\end{array}\right]=\left[\begin{array}{l}
2 \lambda_{\alpha s} v_{\alpha s}+2 \lambda_{\beta s} v_{\beta s} \\
L_{g 1} h_{1} v_{\alpha s}+L_{g 2} h_{1} v_{\beta s}
\end{array}\right]
$$

$\hat{v_{\alpha s}}$ and $\hat{v}_{\beta s}$ are new control inputs.

System (10) is written as:

$$
\left[\begin{array}{c}
\dot{z_{1}} \\
\dot{z_{2}}
\end{array}\right]=\left[\begin{array}{c}
L_{f} h_{2} \\
L_{f} h_{1}
\end{array}\right]+\left[\begin{array}{c}
\hat{v}_{\alpha s} \\
\hat{v}_{\beta s}
\end{array}\right]
$$

A second order linear reference model is introduced as:

$$
\stackrel{\bullet}{z_{m}}=A_{m} z_{m}+B_{m} u_{r e f}
$$

$\left[\begin{array}{l}\dot{z}_{m 1} \\ \dot{z}_{m 2}\end{array}\right]=\left[\begin{array}{cc}-a_{m 1} & 0 \\ 0 & -a_{m 2}\end{array}\right]\left[\begin{array}{l}z_{m 1} \\ z_{m 2}\end{array}\right]+\left[\begin{array}{cc}a_{m 1} & 0 \\ 0 & a_{m 2}\end{array}\right]\left[\begin{array}{l}\lambda_{s}^{* 2} \\ T_{e}^{*}\end{array}\right]$

where $z_{m}$ is the output vector of the reference model; $a_{m 1}$ and $a_{m 2}$ are the positive constants.

The tracking errors between the plant and the reference model are given as:

$$
e_{z}=\left[\begin{array}{ll}
z_{1}-z_{m 1} & z_{2}-z_{m 2}
\end{array}\right]^{T}=\left[\begin{array}{ll}
e_{z 1} & e_{z 2}
\end{array}\right]^{T} .
$$

The error dynamics are derived as follows:

$$
\dot{e}_{z}=A(x)+\bar{V}
$$

where

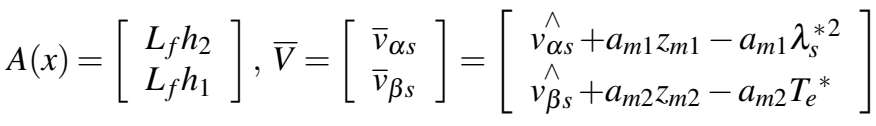
$\bar{v}_{\alpha s}$ and $\bar{v}_{\beta s}$ are new control inputs.

Based on (15), two independent SM switching functions are defined in the vector form

$$
S\left(e_{z}\right)=F e_{z}(x)
$$

where $F \in R^{2 \times 2}$ is a constant non-singular matrix. 
TABLE I

IM'S PARAMETERS

\begin{tabular}{|c|c||c|c|}
\hline Poles & 2 & $R_{s}$ & $2.4 \Omega$ \\
\hline$R_{r}$ & $4.1 \Omega$ & $L_{s}$ & $385 \mathrm{mH}$ \\
\hline$L_{r}$ & $385 \mathrm{mH}$ & $L_{m}$ & $374 \mathrm{mH}$ \\
\hline$P_{n}$ & $2 \mathrm{KW}$ & $f_{n}$ & $50 \mathrm{~Hz}$ \\
\hline
\end{tabular}

It is proven in Appendix A that the following nonlinear controller guarantees the SM reaching condition:

$$
\bar{V}=-F^{-1}[F A(x)+Q \operatorname{sgn}(S)+K S]
$$

where $\operatorname{sgn}($.$) is the sign function and:$

$$
Q=\left[\begin{array}{cc}
q_{1} & 0 \\
0 & q_{2}
\end{array}\right], \quad K=\left[\begin{array}{cc}
k_{1} & 0 \\
0 & k_{2}
\end{array}\right], \quad q_{i}, k_{i}>0 .
$$

\section{AdAPtive InPUT-OUtPUt SM CONTROL}

When the system parameters deviate from the nominal values, especially the resistances $R_{r}$ and $R_{s}$, the tracking error model (15) can be rewritten as:

$$
\begin{aligned}
& \dot{e}_{z 1}=L_{f} h_{2}(x)+\phi_{1} d_{1}(x)+\bar{v}_{\alpha s} \\
& \dot{e}_{z 2}=L_{f} h_{1}(x)+\phi_{2} d_{2}(x)+\bar{v}_{\beta s}
\end{aligned}
$$

or in the compact form

$$
\dot{e}_{z}=[A(x)+\Delta A(x)]+\bar{V}
$$

where $\phi_{i}$ and $\Delta A(x)$ denote uncertainties as follows:

$$
\begin{gathered}
{\left[\begin{array}{ll}
\phi_{1} d_{1}(x) & \phi_{2} d_{2}(x)
\end{array}\right]^{T}=\Delta A(x)} \\
\phi_{1}=2 \Delta R_{s}, \quad \phi_{2}=P\left(\frac{\Delta R_{s}}{\sigma L_{s}}+\frac{\Delta R_{r}}{\sigma L_{r}}\right), \\
d_{1}=-\lambda_{\alpha s} i_{\alpha s}-\lambda_{\beta s} i_{\beta s}, \quad d_{2}=i_{\alpha s} \lambda_{\beta s}-i_{\beta s} \lambda_{\alpha s}
\end{gathered}
$$

Since the system resistances $R_{r}$ and $R_{s}$ are varied with the thermal drift slowly, we assume that $\left|\phi_{i}\right|$ is an unknown and bounded constant.

It is proven in Appendix B that the following nonlinear controller guarantees the convergence of $e_{z 1}$ and $e_{z 2}$ to zero.

$$
\begin{gathered}
\dot{\hat{\phi}}=\gamma_{1} e_{z 1} d_{1} \quad \dot{\hat{\phi}_{2}}=\gamma_{2} e_{z 2} d_{2} \\
\bar{v}_{\alpha s}=-L_{f} h_{2}-\hat{\phi}_{1} d_{1}-k_{1} e_{z 1}-\rho_{1} \operatorname{sgn}\left(e_{z 1}\right) \\
\bar{v}_{\beta s}=-L_{f} h_{1}-\hat{\phi}_{2} d_{2}-k_{2} e_{z 2}-\rho_{2} \operatorname{sgn}\left(e_{z 2}\right)
\end{gathered}
$$

here $\rho_{1}$ and $\rho_{2}$ are positive constants.

\section{Practical RESUlts}

The proposed control scheme is implemented in the block diagram shown in Fig. 4. The error between the reference speed and the measured speed is given to a PI controller. The output of the PI controller is considered as the reference torque. Using (11), (13), (22) and (23) the reference voltages are generated.

The stator flux estimator employed in Fig. 4 is from [20] and it is independent from the adaptive SM controller.

Practical results are obtained for a QIM with the parameters given in table I.
TABLE II

ADAPTIVE SM CONTROLLERS’ PARAMETERS

\begin{tabular}{|c|c||c|c|}
\hline$k_{p}$ & 0.5 & $k_{i}$ & 2 \\
\hline$\gamma_{1}$ & 400 & $\gamma_{2}$ & 400 \\
\hline$\rho_{1}$ & 300 & $\rho_{2}$ & 300 \\
\hline$k_{1}$ & 400 & $k_{2}$ & 450 \\
\hline$a_{m 1}$ & 500 & $a_{m 2}$ & 220 \\
\hline
\end{tabular}

The parameters of the controllers are obtained by trial and error and given in table II. The first row of this table contains the PI coefficients. The experimental rig is illustrated in Fig. 5. A dual-three phase IM drive has been constructed to perform the experimental tests. The switching frequency of the six-phase IGBT inverter has been set at $4 \mathrm{kHz}$. The control software has been implemented on a PC. A Xilinx XC95288 CPLD is used for real time implementation of the switching patterns and to send the data from the A/Ds used to measure the currents and the dc-link voltage. The CPLD board communicates with the PC via a digital Advantech PCI$1751 \mathrm{I} / \mathrm{O}$ board. A second Xilinx XC95108 CPLD is used to calculate and send the speed data from an encoder to the computer through a printer port. The currents are measured using LEM sensors. The control code is written in C. The QIM is obtained by rewinding the stator of a three-phase machine.

To compare the adaptive SM controller, the SM controller and the controller with only $k_{i}$ gains, two practical tests have been done with a $-30 \%$ error in $R_{s}$ and $R_{r}$. In the first test, the ability of the mentioned controllers is examined for direct torque control. The results of this test are shown in Fig. 6. It can be seen that for the adaptive SM controller, the torque and the flux magnitude converge to their references with a good dynamic. The results show the superiority of the adaptive SM controller.

In the second test, the speed control is examined. The results of this test are shown in Fig. 7. The errors of the speeds are shown in this figure. Using the adaptive SM controller, the speed and flux magnitude converge to their references with a better dynamic. In Fig. 7, $\hat{\phi}_{1}$ and $\hat{\phi}_{2}$ are also shown. There is no guarantee on the convergence of $\hat{\phi}_{1}$ and $\hat{\phi}_{2}$ to their real values. In the proof of the stability of the adaptive SM controller, only the convergence of the torque and flux magnitude errors to their references is proven by Barbalat lemma despite uncertainties in $R_{s}$ and $R_{r}$. $\hat{\phi}_{1}$ and $\hat{\phi}_{2}$ are only bounded since the derivative of the Lyapunov function in the proof is negative semi definite. It is worthwhile to note that the aim of the proposed adaptive scheme is to achieve robustness with respect to uncertainties in $R_{S}$ and $R_{r}$ not estimate them.

Another test is conducted, to further verify the decoupling of the control of the torque and the stator flux as well as the capability of the proposed control scheme. Fig. 8 shows the practical results for the speed reversal of the QIM. The speed reference of the QIM is changed from 100 to $-100 \mathrm{rad} / \mathrm{s}$ linearly in 1 second for $t \in[5,6]$ and the stator flux reference is kept constant at $0.4 \mathrm{~Wb}$. The stator flux of the machine is shown in Fig. 8; one can observe from Fig. 8 that the stator flux amplitude remains constant during the speed reversal. The two axis $\alpha-\beta$ voltage references are also shown. 


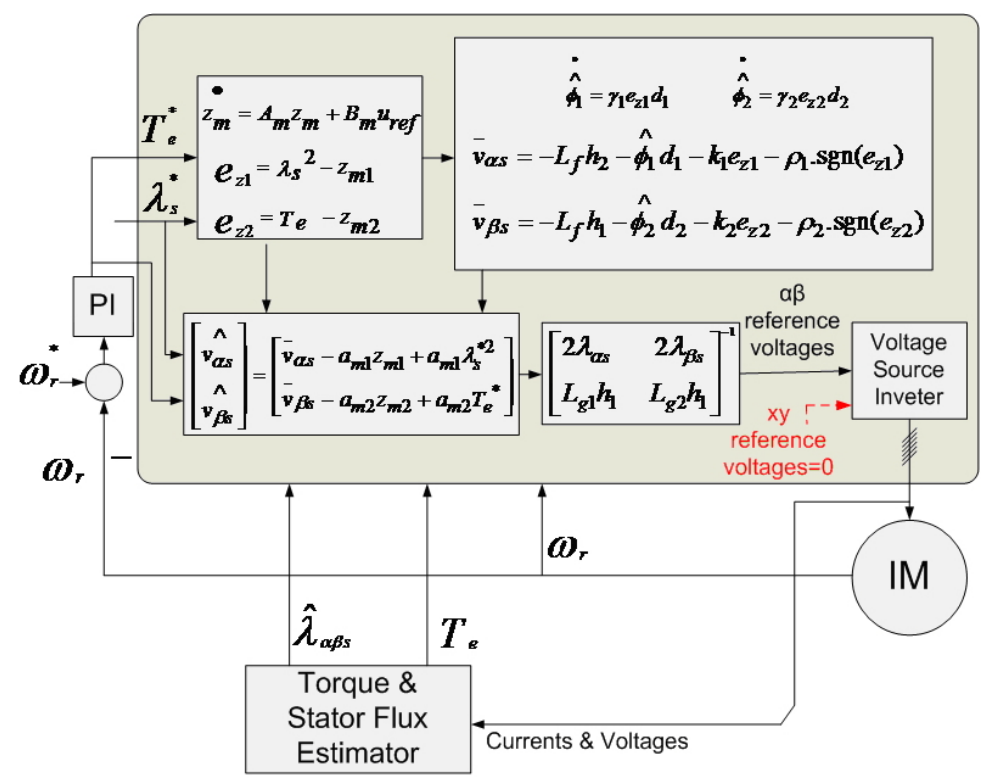

Fig. 4. Drive system block diagram.
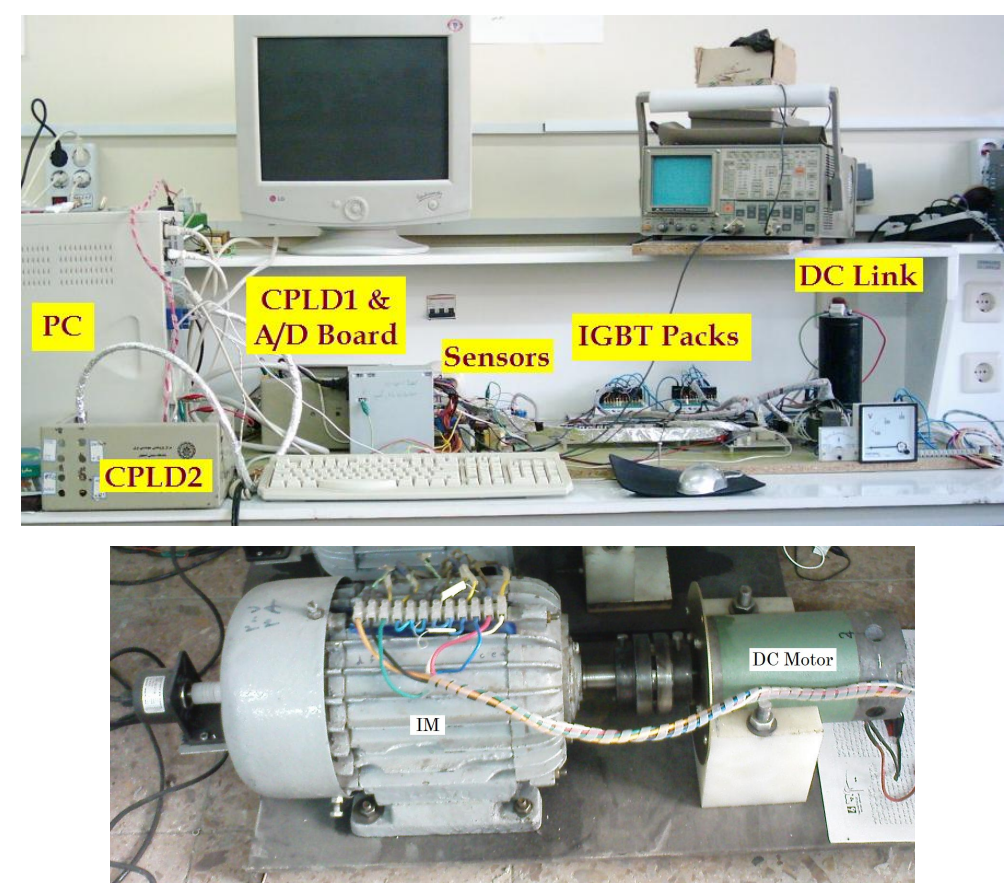

Fig. 5. Experimental rig: PC, CPLD boards and inverter (top), QIM (bottom).

\section{CONCLUSIONS}

This paper discussed a quasi six-phase motor drive which is supplied by a six-phase VSI. An adaptive nonlinear controller has been designed that is capable of controlling the stator flux and the torque of the motor separately. The proposed controller in this paper can track the desired torque and stator flux references in spite of motor resistances mismatching. In addition, the transient dynamic of the motor stator flux and torque is precisely regulated by the design of a linear reference model, since the tracking errors between the statetransformed system and the reference model converge to zero asymptotically.
The effectiveness and validity of the proposed control method is verified by practical results. A comparison between the proposed control schemes is given by experimental tests. When using the adaptive sliding-mode controller the best tracking results are obtained.

\section{APPENDIX A}

Proof of the reachability of the SM controller:

The switching surface dynamics is:

$$
\dot{S}=F \dot{e}_{z}=F A+F \bar{V}=-Q \operatorname{sgn}(S)-K S
$$



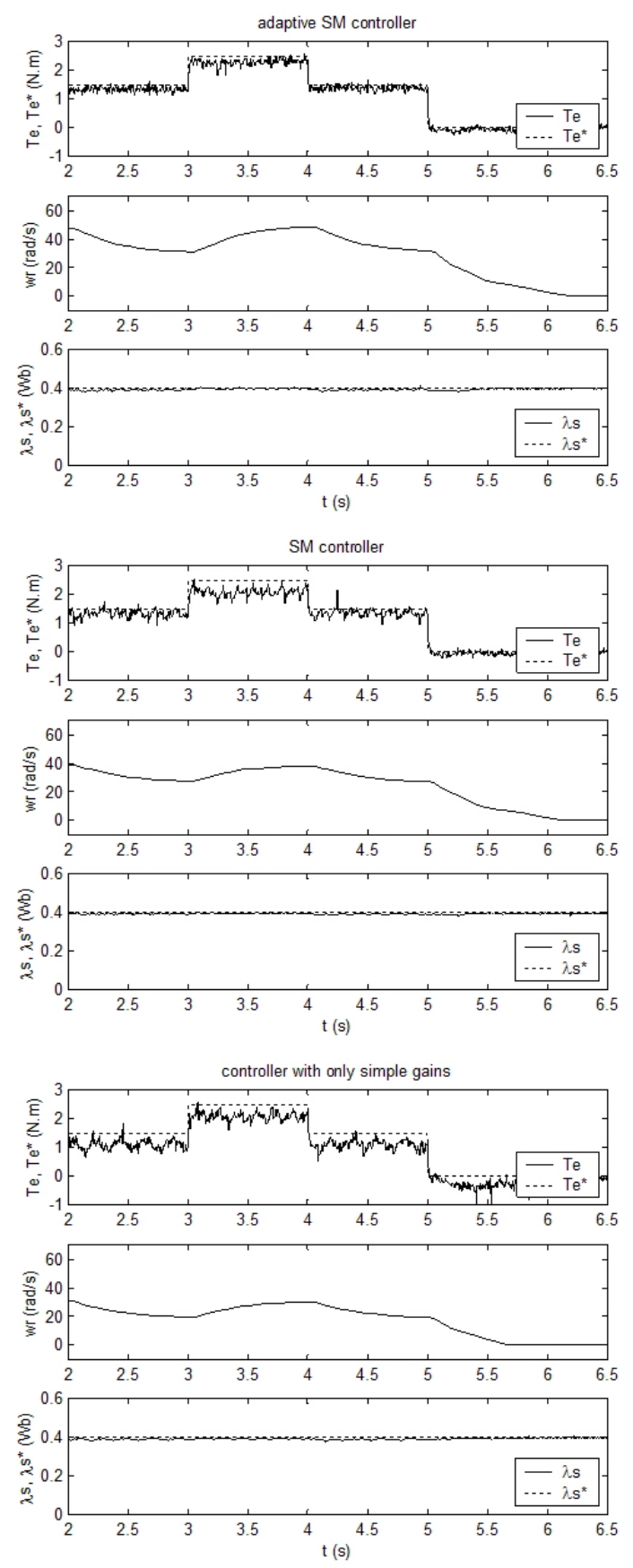
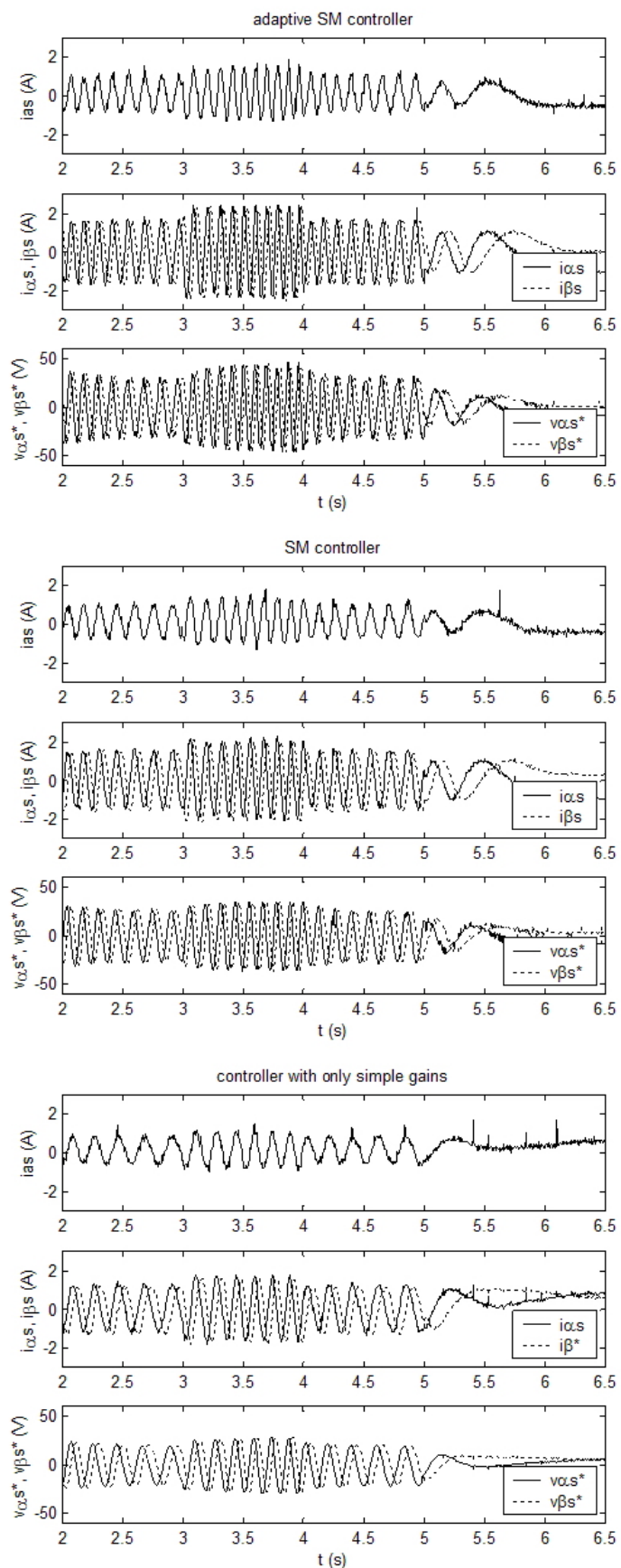

Fig. 6. Direct torque control test of the QIM.

or $\dot{S}_{i}=-q_{i} \operatorname{sgn}\left(S_{i}\right)-k_{i} S_{i}, \quad i=1,2$

then:

$$
S_{i} \dot{S}_{i}=-q_{i} S_{i} \operatorname{sgn}\left(S_{i}\right)-k_{i} S_{i}^{2}=-q_{i}\left|S_{i}\right|-k_{i} S_{i}^{2}<0
$$

Equation (25) guarantees the SM reaching condition.

\section{APPENDIX B}

Proof of the stability of the adaptive SM controller:

Choose the following Lyapunov function:

$$
V=\frac{1}{2}\left\{e_{z 1}^{2}+e_{z 2}^{2}+\frac{1}{\gamma_{1}} \tilde{\phi}_{1}^{2}+\frac{1}{\gamma_{2}} \tilde{\phi}_{2}^{2}\right\}
$$

where $\tilde{\phi}_{i}=\hat{\phi}_{i}-\phi_{i}$ and $\hat{\phi}_{i}$ is the estimate of $\phi_{i}$ and $\gamma_{1}, \gamma_{2}>0$ are constant gains.

Differentiating $V$ with respect to time $t$ one can obtain:

$$
\begin{aligned}
& \dot{V}=\tilde{\phi}_{1}\left\{-e_{z 1} d_{1}+\frac{1}{\gamma_{1}} \dot{\hat{\phi}_{1}}\right\}+\tilde{\phi}_{2}\left\{-e_{z 2} d_{2}+\frac{1}{\gamma_{2}} \dot{\hat{\phi}}\right\}+ \\
& e_{z 1}\left\{L_{f} h_{2}+\bar{v}_{\alpha s}+\hat{\phi}_{1} d_{1}\right\}+e_{z 2}\left\{L_{f} h_{1}+\bar{v}_{\beta s}+\hat{\phi}_{2} d_{2}\right\}
\end{aligned}
$$

Substituting (22)-(23) into (27) one can obtain:

$$
\stackrel{\bullet}{V} \leq-k_{1} e_{z 1}^{2}-k_{2} e_{z 2}^{2} \leq 0 .
$$



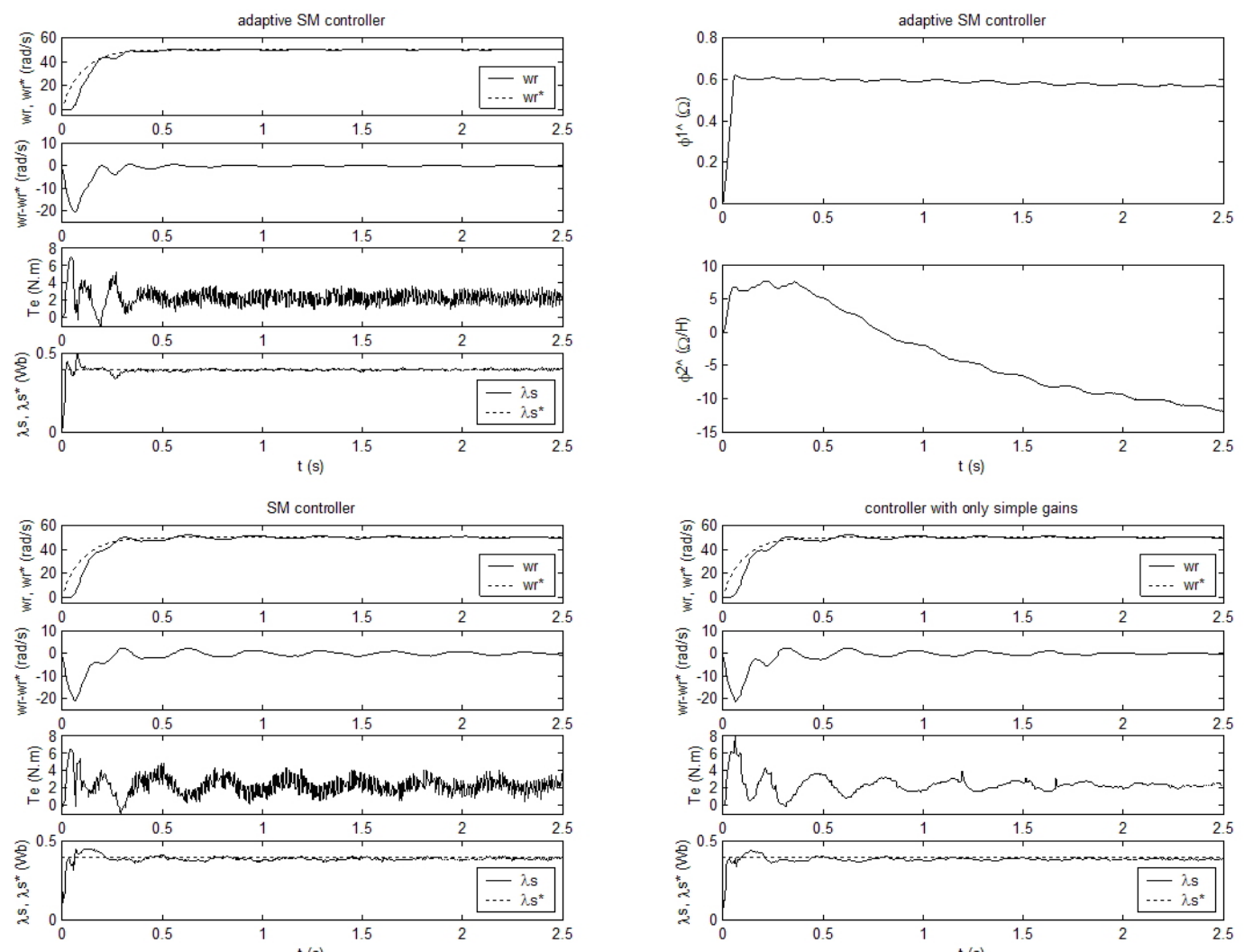

Fig. 7. Speed control test of the QIM.
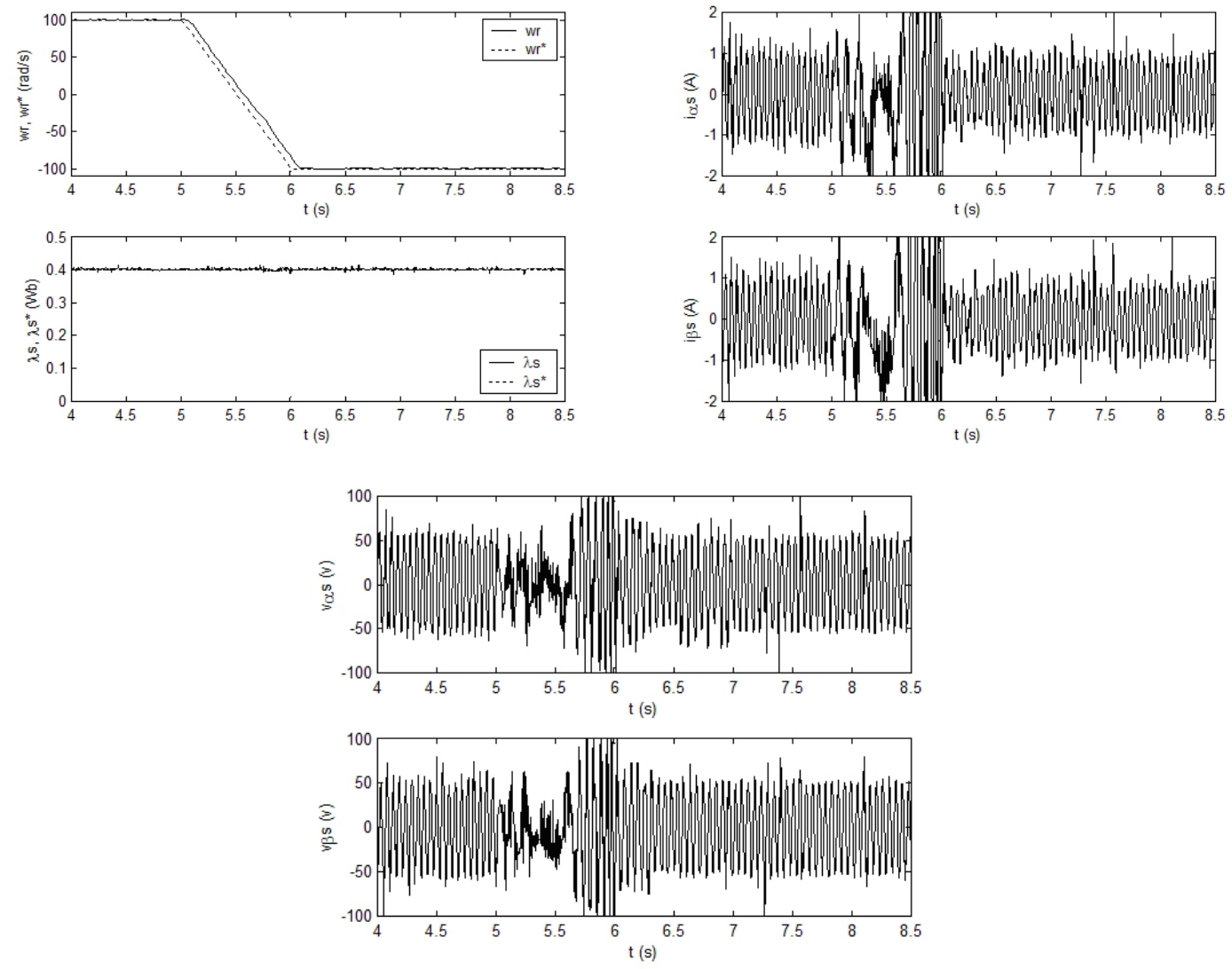

Fig. 8. Speed reversal control test of the QIM using the proposed controller. 
Let:

$$
M(t)=k_{1} e_{z 1}^{2}+k_{2} e_{z 2}^{2} \geq 0 .
$$

Considering (28) and (29):

$$
\begin{aligned}
V(t) & =V\left(e_{z}(0), \hat{\phi}(0)\right)+\int_{0}^{t} \dot{V}(\tau) d \tau \\
& =V\left(e_{z}(0), \hat{\phi}(0)\right)-\int_{0}^{t} M(\tau) d \tau .
\end{aligned}
$$

Since $V(t) \geq 0$ and $V\left(e_{z}(0), \hat{\phi}(0)\right)<\infty$, from (30), it is shown that:

$$
\lim _{t \rightarrow \infty} \int_{0}^{t} M(\tau) d \tau \leq V\left(e_{z}(0), \hat{\phi}(0)\right)<\infty .
$$

As a result, based on Barballat's Lemma [21]-[22]:

$$
\lim _{t \rightarrow \infty} M(t)=0
$$

which guarantees the convergence of $e_{z 1}$ and $e_{z 2}$ to zero if the design parameters $k_{1}, k_{2}$, are chosen to be positive constants.

\section{REFERENCES}

[1] E. Levi, R. Bojoi, F. Profumo, H. A. Toliyat and S. Williamson "Multiphase induction motor drives - a technology status review," IET Electr. Power Appl., Vol. 1, No. 4, pp. 489 516, Jul. 2007.

[2] L. Parsa, "On advantages of multi-phase machines," in Proc. IECONUSA, pp. 1574 1579, 2005.

[3] E. Levi, D. Dujic, M. Jones, and G. Grandi "Analytical determination of DC-bus utilization limits in multiphase VSI supplied AC drives," IEEE Trans. Energy Conv., Vol. 23, No. 2, pp. 433 443, Jun. 2008

4] D. Dujic, G. Grandi, M. Jones, and E. Levi, "A space vector PWM scheme for multifrequency output voltage generation with multiphase voltage-source inverters," IEEE Trans. Ind. Electron., Vol. 55, No. 5, pp. 1943 1955, May 2008.

[5] R. Bojoi, E. Levi, F. Farina, A. Tenconi, and F. Profumo, "Dual threephase induction motor drive with digital current control in the stationary reference frame," IEE Proc.-Electr. Power Appl., Vol. 153, No. 1, pp. 129 139, Jan. 2006.

[6] R. Kianinezhad, B. Nahid-Mobarakeh, L. Baghli, F. Betin, and G.-A. Capolino, "Modeling and control of six-phase symmetrical induction machine under fault condition due to open phases," IEEE Trans. Ind. Electron., Vol. 55, No. 5, pp. 1966 1977, May 2008.

[7] E. Levi, "Multiphase electric machines for variable-speed applications", IEEE Trans. Ind. Electron., Vol. 55, No. 5, pp. 1893 1909, May 2008.

[8] W.-S. Oh, S.-K. Han, S.-W. Choi, and G. W. Moon, "A three phase three-level PWM switched voltage source inverter with zero neutral point potential," Journal of power electr., Vol. 5, No. 3, pp. 224 232, Jul. 2005.

[9] M. G. Hosseini Aghdam, S. H. Fathi, and G. B. Gharehpetian, "Harmonic optimization techniques in multi-level voltage-source inverter with unequal DC sources", Journal of power electr., Vol. 8, No. 2, pp. 171 180, Apr. 2008

[10] M. M. Salem, "Classical controller with intelligent properties for speed control of vector controlled induction motor," Journal of Power Electronis, Vol. 8, No. 3, pp. 210 216, Jul. 2008

[11] B. Castillo-Toledo, S. Di Gennaro, A. G. Loukianov, and J. Rivera, "Hybrid control of induction motors via sampled closed representations," IEEE Tran on Ind. Electr., Vol. 55, No. 10, pp. 3758 3771, Oct. 2008.

[12] S. Maiti, C. Chakraborty, Y. Hori, and M. C. Ta, "Model reference adaptive controller-based rotor resistance and speed estimation techniques for vector controlled induction motor drive utilizing reactive power," IEEE Trans. on Ind. Electr., Vol. 55, No. 2, pp. 594 601, Feb. 2008.

[13] I. Takahashi and Y. Ohmori, "High-performance direct torque control of induction motor," IEEE Trans Ind. Appl., Vol. 25, No. 2, pp. 257-264, Mar./Apr. 1998

[14] R.-J.Wai, "Adaptive sliding-mode control for induction servomotor drive," IEE Proc.-Electr. Power Appl., Vol. 147, No. 6, pp. 553 562, Nov. 2000.

[15] F.-J. Lin, W.-D. Chou, and P.-K. Huang, "Adaptive sliding-mode controller based on real-time genetic algorithm for induction motor servo drive," IEE Proc..-EIetr. Power Appl., Vol. 150, No. 1, pp. 1¹3, Jan. 2003.

[16] C.-M. Lin, and C.-F. Hsu, "Adaptive fuzzy sliding-mode control for induction servomotor systems," IEEE Trans. on Eenergy Conv., Vol. 19 No. 2, pp. 362 368, Jun. 2004

[17] R.-J. Wai, "Fuzzy sliding-mode control using adaptive tuning technique," IEEE Trans. on Ind. Electr., Vol. 54, No. 1, pp. 586 594, Feb. 2007.

[18] H.-J. Shieh, and K.-K. Shyu, "Nonlinear sliding-mode torque control with adaptive backstepping approach for induction motor drive," IEEE Trans. on Ind. Elect., Vol. 46, No. 2, pp. 380 389, Apr. 1999.

[19] Y. Zhao and T. A. Lipo, "Space vector PWM control of dual three-phase induction machine using vector space decomposition," stocktickerIEEE Trans. on Ind. Appl., Vol. 31, No. 5, pp. 1100 1109, Sep./Oct. 1995.

[20] C. Lascu, I. Boldea, and F. Blaabjerg, "Comparative study of adaptive and inherently sensorless observers for variable-speed induction-motor drives," IEEE Trans. on Ind. Electr., Vol. 53, No. 1, pp. 57 65, Feb. 2006.

[21] J. J. E. Slotine, and L. Weiping, Applied nonlinear control, Prentice-Hall, Inc., NJ, 1991.

[22] J. T. Spooner, Stable Adaptive Control and Estimation for Nonlinear Systems: Neural and Fuzzy Approximator Techniques, John Wiley and Sons Inc., NY, U.S.A., 2002

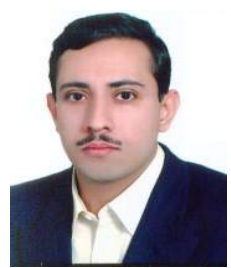

Navid R. Abjadi was born in Isfahan, Iran. He received his B.Eng., M.Sc. and Ph.D. in Electrical Engineering from the Isfahan University of Technology, Isfahan, Iran, in 1999, 2002 and 2010, respectively. He is a lecturer at Shahrekord University. His main research interests include the application of nonlinear control and electric motor drives in general.

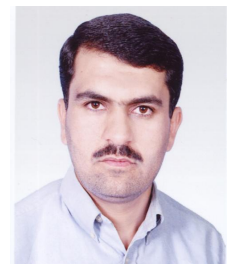

Gholamreza Arab Markadeh was born in Shahrekord, Iran. He graduated from the Isfahan University of Technology, Isfahan, Iran where he obtained his M.S and Ph.D. His main areas of research interest include nonlinear control, power electronics and variable-speed ac drives.

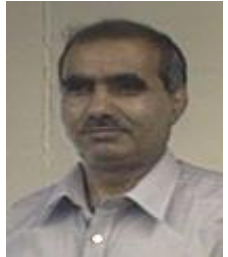

Jafar Soltani was born in Isfahan, Iran. He graduated from Tabriz University, Tabriz, Iran. He holds a M.S and a Ph.D. from UMIST, UK. He is a professor at the Isfahan University of Technology, Isfahan, Iran. His main areas of research include electrical machines and drives. He is a member of IEEE. He has been published in many international journal and conference papers. $\mathrm{He}$ also holds a UK patent. 